\title{
PERBEDAAN HASIL BELAJAR SISWA LAKI-LAKI DENGAN SISWA PEREMPUAN MENGGUNAKAN PEMBELAJARAN KOOPERATIF MODEL MIND MAPPING PADA POKOK BAHASAN KLASIFIKASI MAKHLUK HIDUP SISWA KELAS VII DI SMP IT NURUL MUHAJIRIN BATAM
}

\section{LEARNING OUTCOMES DIFFERENCES BETWEEN MALE AND FAMALE STUDENTS USING COOPERATIVE LEARNING MODEL; MIND MAPPING MODEL ON LIVING CREATURES CLASSIFICATION DISCUSSION AT CLASS VII AT SMP IT NURUL MUHAJIRIN BATAM.}

\author{
Farianti $^{1}$, Rahmi $^{2 *}$, Fenny Agustina ${ }^{3}$ \\ ${ }^{123}$ Program Studi Pendidikan Biologi, FKIP, Universitas Riau Kepulauan,Batam \\ *Korespondensi: Rahmikumbang@gmail.com
}

\begin{abstract}
Abstrak
Penelitian ini bertujuan untuk mengetahui ada tidaknya perbedaan hasil belajar antara siswa lakilaki dengan siswa perempuan dengan menggunakan pembelajaran kooperatif model mind mapping di kelas VII di SMP IT Nurul Muhajirin. Penelitian ini termasuk jenis eksperimen, yakni yang menjadi variabel adalah penerapan pada pembelajaran kooperatif model mind mapping pada siswa laki-laki (X1) dan siswa perempuan (Y2). Data penelitian yang diperoleh adalah hasil belajar siswa laki-laki dan siswa perempuan pada kelas VII yang mengikuti proses pembelajaran dengan pokok bahasan klasifikasi makhluk hidup. Data penelitian diambil dengan menggunakan tes hasil belajar akhir dari pembelajaran berupa tes pilihan ganda. Hasil penelitian diperoleh rata-rata hasil belajar siswa laki-laki 76 dan siswa perempuan 81,57. Uji analisis dilakukan uji $t$ terhadap hasil belajar di dapat $t_{\text {hitung }}=3,723$ dan $t_{\text {tabel }}=2,02$ pada taraf nyata 0,05. Dari perhitungan nilai $t_{\text {hitung }}>t_{\text {tabel }}$ berarti kedua kelas sampel memiliki perbedaan yang signifikan, sehingga $\mathrm{H}_{0}$ ditolak dan $\mathrm{H}_{\mathrm{a}}$ diterima. Dapat disimpulkan bahwa hasil belajar siswa perempuan lebih baik dari hasil belajar siswa laki-laki pada kelas VII menggunakan pembelajaran kooperatif model mind mapping.
\end{abstract}

Kata Kunci : Mind Mapping, Hasil belajar siswa laki-laki dan siswa perempuan, Uji t.

\begin{abstract}
This study aims to determine whether there is a difference student learning outcomes between male and female students using mind mapping model at class VII in SMP IT Nurul Muhajairin. This research was experiments, which the implementation of cooperative learning model; mind mapping the male students (XI) and female students (X2) as variable. The data obtained were male student learning outcomes and female students in class VII is the learning classification of living creatures. The data research was taken using the test results at the the end learning by using multiple choice. the result showed that the average male student learning outcomes 76 points and female students 81.57 points. The test analysis t for learning outcomes got $t_{\text {count }}=3.723$ and $t_{\text {table }}=2,02$ on the level $\alpha=0.05$. based on the calculation $t_{\text {count }}>t_{\text {tabel }}$, it means that both classes of samples have significant differences, so that $H_{0}$ rejected and $H_{a}$ accepted. It can be concluded that the female student learning results is better than male student learning outcomes at class VII by using cooperative learning model; mind mapping.
\end{abstract}

Keywords: Mind mapping, Outcomes learning, Analysis $T_{\text {test }}$ 


\section{PENDAHULUAN}

Manusia belajar, tumbuh dan berkembang dari pengalaman yang diperolehnya melalui kehidupan. Setiap anak dilahirkan dengan perbedaan kemampuan, bakat dan minat. Kemampuan siswa yang satu dengan siswa yang lain itu berbeda. Pada usia sekolah menengah yaitu usia SLTP (Sekolah Lanjut Tingkat Pertama) dan SLTA (Sekolah Lanjut Tingkat Atas), anak berada pada masa remaja atau pubertas. Pertumbuhan laki-laki dan perempuan pun sangat berbeda mulai dari pertambahan tinggi (fisik) maupun kemampuan intelektual berpikirnya.

Permasalahan gender dalam pendidikan merupakan salah satu yang membedakan posisi laki-laki dan perempuan. Perbedaan posisi dan peran tersebut juga menyebabkan perbedaan hasil belajar antara laki-laki dan perempuan. Pada masa SLTP mulai berkembang kemampuan berpikir abstrak. Berpikir abstrak adalah berpikir tentang ide-ide, yang menurut Piaget (1976) dalam Sumantri dan Nana (2006) dikemukakan bahwa berpikir secara formal operasional adalah suatu kemampuan yang telah mengikuti langkah-langkah berpikir ilmiah, dari merumuskan suatu permasalahan sampai dengan menarik kesimpulan dari permasalahan tersebut.

Pada pembelajaran Ilmu Pengetahun Alam khususnya Biologi lebih banyak dijumpai nama-nama ilmiah sehingga perlu dihafal dan diingat kondisi tersebut akan mengakibatkan siswa kurang termotivasi dalam mengikuti proses pembelajaran karena seringkali membosankan. Dengan demikian, belajar Biologi tidak cukup hanya dengan menghafal fakta dan konsep yang sudah jadi, tetapi dituntut pula menemukan fakta-fakta dan konsep-konsep tersebut melalui observasi dan eksperimen. Melalui pelajaran ini siswa dilibatkan secara aktif untuk melakukan eksplorasi alam sehingga berkembang pengalaman belajar siswa tentang Sains. Pada pelajaran IPA Kriteria Ketuntasan Minimum (KKM) di SMP IT Muhajirin adalah 7,5. Siswa umumnya malas untuk membaca bukubuku pelajaran. Mereka lebih memilih belajar hasil ringkasan atau rangkuman dari LKS (Lembar Kerja Siswa). Siswa akan merasa berat untuk membuat rangkuman sendiri. Menghadapi kondisi seperti itu, pada umumnya guru dalam proses pembelajaran seringkali hanya berdasarkan pada pemenuhan kebutuhan siswa rata-rata (sudah memenuhi KKM). tetapi bisa juga karena faktor lain yang timbul dari dalam diri anak, seperti kondisi fisik dan kesehatan, motivasi belajar, dan dari luar kondisi sekolah, lingkungan rumah, serta masyarakat. 
Dalam penelitian ini mencoba mengangkat permasalahan apakah ada perbedaan hasil belajar siswa laki-laki dan siswa perempuan dalam proses pembelajaran. Untuk menumbuhkan hal tersebut perlu adanya kegiatan yang dapat mendorong agar siswa dapat ikut serta dalam proses pembelajaran. Mind Mapping salah satu cara untuk membuat siswa lebih kreatif lewat gagasan yang di dapat melalui tulisan-tulisan pemetaan yang bermakna.

Sehubungan dengan permasalahan di atas, dan hasil penelitian Risdawati $d k k$. (2012) yang mengemukakan bahwa terdapat pengaruh positif yang berarti pada penggunaan model Mind Mapping terhadap hasil belajar siswa, dengan kata lain dapat meningkatkan hasil belajar Biologi. Maka, penulis mencoba melakukan penelitian terhadap hasil belajar siswa dalam mencapai kompetensi dengan model tersebut. Mind Mapping yang merupakan pembelajaran kooperatif yang pada dasarnya adalah belajar bersama pada kerja kelompok. Namun diharapkan siswa dapat berkompetisi untuk menjadi yang terbaik. Berdasarkan batasan masalah dan rumusan masalah yang dijumpai, maka tujuan penelitian yang akan di capai yaitu untuk membuktikan perbedaan hasil belajar siwa laki-laki dengan perempuan kelas VII menggunakan pembelajaran kooperatif model Mind Mapping pada pokok bahasan klasifikasi makhluk hidup di SMP IT Nurul Muhajirin Batam?"

\section{METODOLOGI}

Penelitian ini dilaksanakan selama kurang lebih 3 (tiga) bulan, pada akhir April sampai dengan akhir bulan Mei 2014 sedangkan lokasi atau tempat dilaksanakan penelitian ini adalah SMP IT Nurul Muhajirin, Kecamatan sekupang Kota Batam. Jenis penelitian kuantitatif dengan metode penelitian eksperimen. Menurut Arikunto (2006) metode eksperimen adalah untuk melihat hubungan antara dua variabel atau lebih atau mencari pengaruh suatu variabel terhadap variabel lainnya. Penelitian dilaksanakan dengan menggunakan Posttest Only Design dalam rancangan ini digunakan dua kelompok subjek siswa laki-laki dan siswa perempuan. Pada kedua kelompok tersebut diberi posttest setelah dilaksanakan perlakuan model pembelajaran. Pola desain yang dapat digunakan terlihat pada Tabel 1. 
SIMBIOSA Vol 5 (1): 16-24 Juli 2016

Farianti, Rahmi, Fenny Agustina: Perbedaan hasil belajar siswa laki-laki...

Tabel 1. Desain Rancangan Penelitian

\begin{tabular}{cccc}
\hline Penelitian & Variabel Bebas & $\begin{array}{c}\text { Variabel } \\
\text { Terikat }\end{array}$ & POST TES \\
\hline Eksperimen & $\mathrm{X}$ & $\mathrm{Y} 1$ & $\mathrm{~T} 1$ \\
Eksperimen & & $\mathrm{Y} 2$ & $\mathrm{~T} 2$ \\
\hline
\end{tabular}

\section{Keterangan :}

$\mathrm{X}=$ Penerapan pada model pembelajaran kooperatif metode mind mapping.

$\mathrm{T} 1=$ Tes kemampuan akhir (posttest) pada kelas laki-laki

$\mathrm{T} 2=$ Tes kemampuan akhir (posttest) pada kelas perempuan

Variabel dalam penelitian ini terdiri dari 2 (dua) variabel yaitu : a) Variabel Bebas (X) adalah metode yang digunakan dalam penelitian yaitu model mind mapping. Variabel Terikat (Y) adalah hasil belajar IPA khususnya Biologi pada siswa laki-laki dan perempuan kelas VII. Materi pembelajaran dengan pokok bahasan Klasifikasi Makhluk Hidup. Pengumpulan data dilakukan dengan pemberian tes yang bersifat objektif/pilihan berganda berjumlah 50 butir soal yang belum divaliditasi. Setiap soal memiliki nilai dikotomi 1 dan 0 . Untuk setiap jawaban yang benar mendapat nilai 1 sedangkan untuk jawaban yang salah mendapat nilai 0. Sehingga diperoleh skor maksimal adalah 50 dan skor minimal adalah 0 .

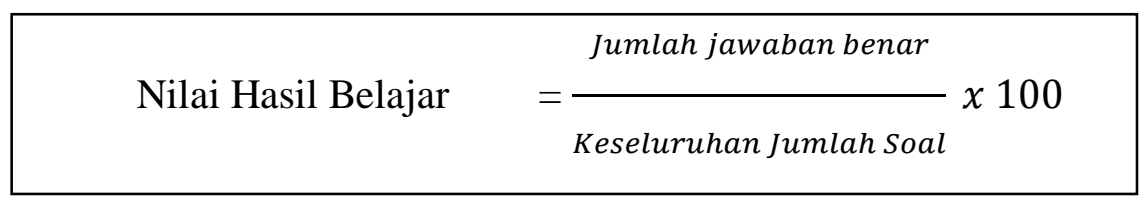

Sebelum dilakukan analisis data, instrument tes hasil belajar dikalibrasi guna melihat apakah valid setiap soalnya. Data-data ini merupakan tes hasil belajar siswa selama proses pembelajaran berlangsung. Teknik pengumpulan data dalam penelitian ini, berupa : data primer hasil belajar siswa laki-laki dan siswa perempuan dan pengambilan gambar saat proses pembelajaran. Populasi pada penelitian ini adalah siswa kelas VII SMPIT Muhajirin Batam yang berjumlah 89 orang.

Tabel 2. Jumlah Siswa Kelas VII

\begin{tabular}{cccc}
\hline Kelas & Laki-laki & Perempuan & Jumlah \\
\hline VII.1 & 30 & -- & 30 \\
VII.2 & 29 & -- & 29 \\
VII.3 & -- & 30 & 30 \\
\hline
\end{tabular}


Adapun teknik pengambilan sampel yang digunakan dalam penelitian ini adalah teknik sampling non acak dengan Purposive sampling. Menurut Mulyatiningsih, (2011) Purposive sampling yaitu apabila sasaran sampel yang diteliti memiliki karakteristik tertentu yang diambil sudah ditetapkan sehingga dinamakan sampel bertujuan. Dalam penelitian ini telah memiliki karakteristik yaitu berdasarkan jenis kelamin antara laki-laki dan perempuan.serta dilakukan dalam 3 tahap yaitu : tahap persiapan yaitu langkah awal sebelum dilakukan penelitian seperti observasi dan menyusun rencana pembelajaran; tahap pelaksanaan yaitu langkah-langkah yang dilakukan saat peoses penelitian berlangsung (sintakdan pelaksaan pembelajaran); tahap pengumpulan dan pengulahan data saat penelitian telah selesai dilakukan (Riyanto, 2010). Analisis instrumen penelitian adalah sebagai berikut: a) Validitas adalah suatu ukuran yang menunjukkan tingkat keshahihan suatu instrumen. Pengujian validitas instrument tes menggunakan teknik korelasi point biserial yang digunakan untuk satu variabel diukur dalam skala interval/rasio dan variabel lainnya adalah variabel nominal dengan dua tingkatan klasifikasi /variabel dikotomi (Arikunto, 2006); b) Reliabilitas, adalah mengetahui tingkat ketepatan (precition) dan keajengan (consistency) skor tes. Indek reliabilitas ini berkisar antara 0 sampai 1. Semakin tinggi koefisien reliabilitas suatu tes (mendekati 1), maka semakin tinggi pula keajengan/ketepatannya. Untuk mengetahui koefisien reliabilitas tes soal bentuk pilihan ganda dapat digunakan rumus Kuder Richarson (KR-20) (Sugiyono, 2013); c) Uji Normalitas, untuk mengetahui apakah populasi berdistribusi normal atau tidak. Pengujian normalitas dari data menggunakan rumus Chi Kuadrat yang digunakan untuk menguji hipotesis komparatif $\mathrm{k}$ sampel independen, dengan data berbentuk nominal (Sugiyono, 2013); d) Uji Homogenitas Varians menentukan apakah adanya suatu variasi yang homogen pada kelompok data menggunakan Uji $F$ (Kasmadi dan Nia, 2013). Nilai F dapat digunakan untuk mengetahui pengaruh variabel bebas secara bersama-sama terhadap variabel terikat (Sugiyono, 2013); dan e) Pengujian Hipotesis digunakan untuk membandingkan rerata kedua kelompok data menggunakan anava pada taraf signifikasi $\alpha$ $=0.05$ dengan menggunakan uji t. Uji t dapat digunakan bila jumlah anggota sampel $n_{1}=$ $\mathrm{n}_{2}$, dan varian homogen maka dapat digunakan rumus $t$-test (Sugiyono, 2013). 


\section{PEMBAHASAN}

Data penelitian yang sudah diperoleh akan dilakukan penghitungan dengan menggunakan program Microsoft Excel. Sebelum proses penelitian dilakukan persiapan instrumen mulai dari validitas butir soal, uji reliabilitas. Pengujian validitas untuk validasi butir-butir soal menggunakan Uji Point Biserial Correlation. Hasil uji coba instrumen yang terdiri 50 butir soal dalam bentuk pilihan ganda. Dari jumlah soal tersebut ada soal yang valid dan ada juga soal yang drop. Untuk soal yang dinyatakan valid berjumlah 23 butir soal jika diprosentasekan maka soal yang valid berkisar $46 \%$ sedangkan sisanya dinyatakan drop berjumlah 27 butir soal dan jika diprosentasekan berkisar soal yang drop tersebut adalah 54\%. Data validitas butir soal valid dan drop dapat dilihat pada Tabel 1 . Tabel 3. Data Validitas Butir Soal Valid dan Drop

\begin{tabular}{cccc}
\hline KATEGORI & NOMOR SOAL & JUMLAH & TOTAL \\
\hline $\boldsymbol{V A L I D}$ & $3,5,7,8,9,10,11,13,15,16,18,19,20,25,26$, & 23 & 50 \\
\multirow{2}{*}{$\boldsymbol{R} \boldsymbol{O P P}$} & $28,30,36,37,38,43,45,49$ & & \\
& $1,2,4,6,12,14,17,21,22,23,24,27,29,3,32$, & 27 & \\
\hline
\end{tabular}

Sedangkan untuk rekapitulasi data berdasarkan prosentase jumlah butir soal yang valid dan butir soal drop dapat divisualkan ke dalam grafik berbentuk Pie, seperti pada Gambar 1.

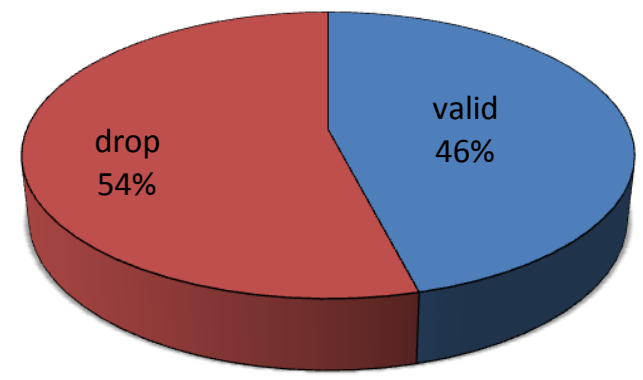

Gambar 1. Prosentase Butir Soal Valid dan Drop

Reliabilitas menunjukkan sejauh mana suatu alat pengukur dapat dipercaya atau diandalkan, analisis Kuder Richarson (KR-20 didapat nilai reliabilitasnya $\mathrm{r}_{\mathrm{kk}}=0,867$. Berdasarkan nilai acuan tersebut, maka instrumen tes hasil belajar mempunyai tingkat korelasi sangat tinggi, yakni berada diatas 0,80 . Sedangkan uji reliabilitas sangat baik. 
Berdasarkan perlakuan penelitian yang dilakukan pada masing-masing kelas sampel, maka diperoleh data hasil belajar Biologi siswa pada pokok bahasan klasifikasi makhluk hidup dengan menggunakan pembelajaran kooperatif model Mind Mapping didapat nilai yang bervariatif antar ke dua variabel yang diujikan. Model Mind Mapping dapat meningkatkan kreatifitas dan keaktifan siswa dalam mengingat materi yang diberikan saat pembelajaran berlangsung.

Pada perlakuan penelitian siswa perempuan lebih kreatif dalam pembuatan Mind Mapping dibandingkan siswa laki-laki, hal ini dapat dilihat dari contoh Mind Mapping hasil pembelajaran kooperatif maupun hasil belajar yang diperoleh lebih tinggi dibandingkan dengan siswa laki-laki. Pemahaman dalam proses pembelajaran sangat mendukung yang diikuti oleh apa yang divisualkan yaitu pada mind map yang dibuat. Hal ini dapat dilihat dari nilai kedua kelas sampel. Kelas laki-laki nilai tertinggi adalah 91, nilai terendah adalah 60 dan rerata nilai adalah 75,5. Sedangkan untuk kelas perempuan niali tertinggi adalah 96 dan rerata nilai adalah 81,57.

Dilihat dari nilai KKM di SMP IT Nurul Muhajirin untuk mata pelajaran Biologi adalah 7,5, dari jumlah siswa 30 orang pada kelas laki-laki yang memperoleh nilai dibawah KKM adalah 14 orang siswa, sedangkan untuk kelas perempuan yang berjumlah 30 orang yang memperoleh nilai di bawah KKM adalah 3 orang siswa maka siswa lakilaki memperoleh nilai di bawah KKM lebih banyak dibandingkan kelas siswa perempuan. Jika dilihat dari persentase ketuntasan siswa laki-laki hanya memperoleh 53,33\% yang tuntas sedangkan siswa perempuan berkisar 90\%. Dari data persentase siswa menunjukkan perbedaan daya pikir dan juga pemahaman antara laki-laki dan perempuan. Siswa laki-laki lebih aktif tapi sedikit kreatif dalam hal menulis atau bersifat visual juga keaktifannya yang menyebabkan siswa laki-laki tidak dapat fokus karena sulit diatur ini menyebabkan hasil belajarnya rendah. Didukung oleh pendapat Dijk (1975) dalam Nuryoto (1998) prestasi akademik perempuan lebih baik dibandingkan dengan laki-laki, Perempuan memiliki comparative advantage pada bidang pendidikan. Mereka lebih tekun, lebih teliti dan bersedia mendengarkan dengan baik. Sikap emosionalnya lebih dominan dibandingkan pada kemampuan fisiknya. Sedangkan siswa perempuan lebih menyukai kreatifitas dalam hal menulis dan membaca juga menyelesaikan pekerjaan dengan baik.

Untuk proses evaluasi hasil yang diperoleh kelas siswa laki-laki sedikit bervariatif hampir bernilai sama hal ini bisa jadi siswa laki-laki melakukan kecurangan atau 
bekerjasama menjawab soal hal ini disebabkan siswa laki-laki saat pembelajaran tidak fokus dan kurang memperhatikan saat guru sedang sedang menjelaskan dan lebih banyak bermain atau sibuk dengan kegiatan masing-masing hanya beberapa siswa yang memperhatikan dengan baik sehingga dapat dilihat nilai ketuntasan 53,33\%. Jadi, pembelajaran kooperatif dengan model Mind Mapping memberikan perbedaan nilai hasil belajar Biologi pada siswa laki-laki dengan siswa perempuan.

Dengan menggunakan model Mind Mapping yang dilakukan dapat memberikan dan juga meningkatkan motivasi dalam belajar karena dalam proses pembelajaran tidak menimbulkan kebosanan (Aripin, 2013) dan siswa di tuntut untuk menuangkan ide-ide baru dan kreatifitasnya agar Mind Map yang dibuat menjadi menarik dan mudah dipahami khususnya pada pokok bahasan klasifikasi makhluk hidup pada pelajaran Biologi. Selain menyenangkan setiap proses pembelajaran dengan menggunakan Mind Mapping juga ditemukan beberapa kekurangan yaitu seperti siswa yang kurang kreatif akan lebih sulit untuk menuangkan ide dan gambar, dan membutuhkan waktu yang lama sehingga untuk pokok bahasan klasifikasi butuh waktu yang banyak selain materi yang ada juga banyak sehingga dibutuhkan pembagian pembelajaran dengan baik agar materi dapat tersampaikan dan hasil dapat memuaskan.

\section{KESIMPULAN}

Pada hasil belajar antar siswa laki-laki dengan siswa perempuan kelas VII pada pokok bahasan klasifikasi makhluk hidup di SMP IT Nurul Muhajirin Batam, diperoleh hasil belajar untuk rata-rata nilai pada siswa laki-laki 75,5 dan siswa perempuan memperoleh nilai rata-rata 81,57. Hasil pengujian hipotesis diperoleh $\mathrm{t}_{\text {hitung }}$ lebih besar daripada $\mathrm{t}_{\text {tabel }}(3,723>2,0042)$ maka $_{\mathrm{Ho}}$ ditolak dan ${ }_{\mathrm{Ha}}$ diterima. Dapat disimpulkan bahwa terdapat perbedaan yang signifikan antara hasil belajar siswa laki-laki dan siswa perempuan yang melakukan pembelajaran kooperatif model Mind Mapping. Saran agar dapat diupayakan dalam proses pembelajaran untuk materi tertentu menggunakan kooperatif model Mind Mapping.

\section{REFERENSI}

Amri, S dan Iif K.A, 2010. Proses Pembelajaran Kreatif dan Inovatif Dalam Kelas. Cetakan pertama. Penerbit Prestasi Pustaka. Jakarta. 
Arikunto, S. 2006. Prosedur Penelitian Suatu Pendekatan Praktik. Cetakan ketiga belas. Penerbit PT.Rineka Cipta. Jakarta.

Aripin, B. 2013. Penerapan Metode Mind Mapp Dalam Pembelajaran Sumber Daya Alam Untuk meningkatkan Motivasi Peserta Didik Kelas IV Di MI Wahid Hasyim Sleman Tahun Pelajaran 2012/2013. [Skripsi], Universitas Islam Negeri Sunan Kalijaga. Yogyakarta.

Buzan, T. 2007. Buku Pintar Mind Map Untuk Anak. Cetakan Kedua. Penerbit Gramedia Pustaka Utama. Jakarta.

Kasmadi dan Nia, S. 2013. Panduan Modern Penelitian Kuantitatif. Cetakan Pertama. Penerbit Alfabeta. Bandung.

Latisma, D.J 2011. Evaluasi Pendidikan. Cetakan pertama. Press. Universitas Negeri Padang. Padang.

Mulyatiningsih, E. 2011. Metode Penelitian Terapan Bidang Penddidikan. Cetakan pertama. Penerbit Alpabeta. Jakarta.

Nuryoto. 1998. Perbedaan Prestasi Akademik Antara Laki-laki dan Perempuan Studi Di Wilayah Yogyakarta. Jurnal Psikologi Volume 2, [hal 16-24].

Risdawati, Renny, Rio F, Siska N. 2012. Pengaruh Pembelajaran Kooperatif Tipe STAD dengan Menggunakan Mind Map Terhadap Hasil Belajar Biologi Pada Siswa Kelas VII SMPN 1 Bayang Kab.Pesisir Selatan Tahun Pelajaran 2011/2012. Sumatera Barat. Jurnal [13 maret 2014 ; akses pukul 10:44 WIB].

Slavin. R.E. 2009. Cooperative Learning (Teori, Riset dan Praktis). Cetakan Keempat. Penerbit Nusa Media. Bandung.

Sudjana, N. 2009. Dasar- Dasar Proses Belajar Mengajar. Cetakan : Kesepuluh. Penerbit Sinar Baru Algensindo. Bandung.

Suprijono, A. 2009. Cooperative Learning (Teori dan Aplikasi PAIKEM). Penerbit Pustaka Pelajar. Jakarta.

Widowati, A. 2010. Proposal Penelitian : Pengaruh Mind Map Terhadap Kemampuan Kognitif dan Kreatifitas Siswa Dalam Pembelajaran Sains Meaningfully. Universitas Negeri Yogyakarta. Yogyakarta. [13 maret 2014. Akses Pukul 10:33 WIB].

Yohanes. 2012. Diktat Pendekatan Strategi, Metode, Teknik dan Model Pembelajaran. Universitas Negeri Padang Press. Padang. 